\title{
Erratum to: Measurement and mechanical analysis of the strains- stresses induced by tree-pulling experiments in tree stems
}

\author{
Yijun $\mathrm{Wu}^{1} \cdot$ Zhuoping Shao ${ }^{1}$
}

Published online: 7 October 2016

(c) Springer-Verlag Berlin Heidelberg 2016

\section{Erratum to: Trees (2016) 30:675-684 \\ DOI 10.1007/s00468-015-1310-4}

Unfortunately, the part Acknowledgments was missing in the original publication and the corrected version is given below:

Acknowledgments The study was supported by the National Natural Science Foundation of China (No. 31570715). The authors wish to thanks anonymous reviewers for critically reviewing previous drafts. The author also thanks Dave Baier for our manuscript language editing.

The online version of the original article can be found under doi: $10.1007 / \mathrm{s} 00468-015-1310-4$.

\section{Zhuoping Shao}

szp8@163.com

1 College of Forestry, Anhui Agricultural University, 130 West Changjiang Rd., Hefei 230036, China 